\title{
C-14 dating and the disappearance of Norsemen
}

\section{from Greenland}

J.Arneborg' ${ }^{1}$ J. Heinemeier ${ }^{2}$, N. Lynnerup ${ }^{3}$, H.L. Nielsen ${ }^{2}$, N. Rud ${ }^{2}$ and A.E. Sveinbjörnsdóttir ${ }^{4}$

'SILA - The Greenland Research Center at The National Museum of Denmark, DK-1220 Copenhagen, Denmark

${ }^{2} A M S{ }^{14} \mathrm{C}$ Dating Laboratory, Institute of Physics and Astronomy, University of Aarhus, DK-8000 Aarhus C, Denmark

${ }^{3}$ Laboratory of Biological Anthropology, The Panum Institute, University of Copenhagen, DK-2000 Copenhagen, Denmark

${ }^{4}$ Science Institute, University of Iceland, IS-107 Reykjavik, Iceland

$D$ irect counting of ${ }^{14} \mathrm{C}$ atoms by Accelerator Mass Spectrometry (AMS), introduced in 1977 , allows radiocarbon $\left({ }^{14} \mathrm{C}\right)$ dating of samples of less than $0.1 \mathrm{mg}$ carbon-10.000 times smaller than required for traditional ${ }^{14} \mathrm{C}$-dating based on betadecay counting $[1,2]$. The AMS ${ }^{14} \mathrm{C}$ Dating Laboratory in Aarhus participates in a study of the Norse (Viking) culture in Greenland with special emphasis on the time development of human diet-quantified via ${ }^{14} \mathrm{C}$ dating and measurements of stable-isotope composition of bone collagen. This example of applied physics is described in the following.

\section{The Norse colonies in Greenland}

In the Middle Ages European civilisation was brought to Iceland and Greenland by Norsemen-people closely related to the Vikings who some generations before had raided and settled in Britain and on the coasts of the European continent. The settlers took land in Iceland from about AD 900, and from Iceland they founded colonies in Greenland. The first settlers in Iceland were farmers from Norway and the northern British Isles who crossed the sea in their longships loaded with families and cattle, sheep, goats, horses, pigs, cats and dogs. According to the tradition Icelandic settlers led by the outlaw Erik the Red sailed further west in 985 to establish a new colony on the South West coast of Greenland. The adventurous story of the first Norse settlers in Greenland is told in colourful detail in the sagas, a treasure of literature written down in Iceland around 1200. However, a no less fascinating story of the Norse settlers emerges from the application of the methods of physics to their remains, unearthed through a century of archeological excavations in Greenland.

In Greenland the Norsemen established colonies with farms, churches, cloisters and a bishopric: the Eastern Settlement near the southern tip of Greenland and the Western Settlement further north, near the present-day capital Nuuk. The total population was not more than a few thousand at any time. In spite of their harsh surroundings, these remote outposts maintained good connections back to Europe-there were-at least in the first centuries - regular ship crossings between Greenland, Iceland, Norway and the rest of Europe. Already in the early days of the colonies, Norsemen visited North America, nearly five centuries before Columbus [3]. However, the adventure only lasted about 450 years - the Norsemen seem to have disappeared completely from Greenland some time during the late 1400 's. But why did the Norsemen succumb while the Eskimos prospered? Exactly what happened is still a mystery and has been a subject of heated debate for many years. Arguments have been made for causes such as deteriorating climate, overgrazing, epidemic diseases, inbreeding, English pirates, hostile Eskimos, a dwindling market for export of walrus tusks - or a combination of these.
In the following we describe a physics approach to the problem of the Greenland Norse made possible through a joint interdisciplinary effort [4].

As a result of 80 years of excavations in Greenland, The Danish National Museum possesses a large collection of bones from burials in churchyards in the old Norse colonies. Stable-isotope analysis of selected parts of this bone material has enabled us to determine which kind of food each individual has eaten - or more precisely: the balance between terrestrial and marine diet (Box 3). At the same time, we have ${ }^{14} \mathrm{C}$ dated the bones by the AMS technique (Box 1 and 2). We cannot claim to have solved the enigma of the disappearance of the Norsemen from Greenland, but we can at least exclude some hypotheses. The isotope analysis indicates that the Norsemen changed their dietary habits. The diet of the first settlers consisted of $80 \%$ agricultural products and $20 \%$ food from the surrounding sea. But seafood played an increasing role, such that the pattern was completely turned around towards the end of the period-from the 1300's the Greenland Norse had $50-80 \%$ of their diet from the marine food chain. In simplified terms: they started out as farmers but ended up as hunters/fishers. Some archeologists have claimed that the Greenland Norsemen succumbed because they-being culturally inflexible-either could not or would not adapt to changing conditions and therefore came to a catastrophic end, triggered by deteriorating climate. This hypothesis may now be refuted.

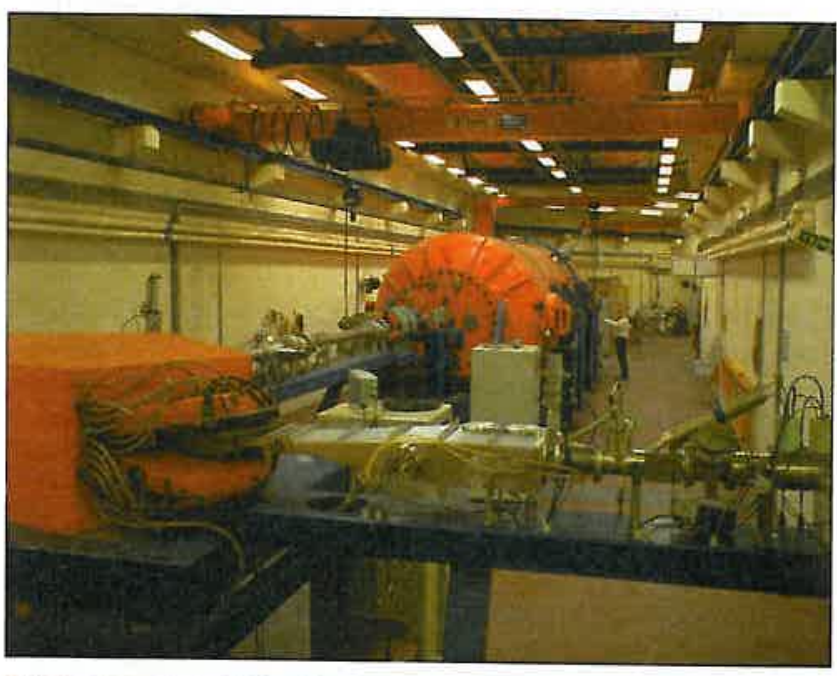

Fig. 1: The tandem accelerator at the Institute of Physics and Astronomy, now used mainly for AMS ${ }^{14} \mathrm{C}$ dating. About 1000 samples are ${ }^{14} \mathrm{C}$ dated annually. Sample sizes down to as little as $0.1 \mathrm{mg}$ of carbon can be handled. 
So far, our knowledge of the development of the Norse culture in Greenland has mainly been based on written sources and excavations of Norse buildings, farms and churchyards. Excavations of kitchen middens at the farms have indicated an economy based on animal husbandry and seal hunting, but the results are difficult to quantify. It is not certain what proportion of bones from the various food sources actually ended up in the midden and if so, to what extent they have survived decomposition. For example, the absence of fishbone in the middens does not prove that the Norse did not eat fish. Not only will fishbone rapidly decay in a midden, more likely they never got there in the first place-fishbone is a food source highly appreciated by, e.g., birds, dogs and pigs. In fact, the isotopes have revealed that dogs are often more marine than their masters.

\section{Carbon-14 dating of human bone}

To determine the subsistence pattern and a possible time trend that might have been caused by, e.g., adaptation to changing living conditions a more direct approach is needed, preferably analysis of the remains of the people themselves by physics methods. Human bone is essentially the only datable material in the graves, since occurrence of grave goods virtually ceased with Christianity. This precious bone material-skeletal parts of about 450 individuals - has been brought to light by Danish excavations since 1921. Nearly all churchyards known from the written sources are represented. However, since a traditional ${ }^{14} \mathrm{C}$ dating would consume a major part of, for example, a human thighbone, researchers have practically refrained from that type of dating.

\section{Box 1}

\section{The carbon-14 method}

The ${ }^{14} \mathrm{C}$ dating of material of biological origin is based on measurement of the isotopic ratio of radioactive ${ }^{14} \mathrm{C}$ to stable carbon $\left({ }^{12} \mathrm{C}\right.$ and $\left.{ }^{13} \mathrm{C}\right)$. The ${ }^{14} \mathrm{C}$ is produced by cosmic-ray bombardment of the atmosphere in a quasi-stationary equilibrium resulting in an approximately constant atmospheric ${ }^{14} \mathrm{C} /{ }^{12} \mathrm{C}$ value of $\approx 1.2 \cdot 10^{-12}$. Since atmospheric $\mathrm{CO}_{2}$ via photosynthesis in plants enters the entire food chain, nearly the same isotopic ratio applies to the carbon of all living organisms. When the organism dies, the equilibrium is broken and the ${ }^{14} \mathrm{C} /{ }^{12} \mathrm{C}$ ratio decreases exponentially with a 5730 years half-life. Thus, from a measurement of ${ }^{14} \mathrm{C} /{ }^{12} \mathrm{C}$ value for the remains of the organism, the age can be determined. However, since the atmospheric ${ }^{14} \mathrm{C} /{ }^{12} \mathrm{C}$ has varied considerably (more than 10\%) in the past, the exponential decay law cannot be used directly. Instead, the age is determined from a comparison with precise ${ }^{14} \mathrm{C} /{ }^{12} \mathrm{C}$ data for tree rings of known (dendrochronological) age. This so-called tree-ring calibration reaches 10,000 years back. Due to varying ${ }^{14} \mathrm{C}$ production rate the ${ }^{14} \mathrm{C} /{ }^{12} \mathrm{C}$ value of tree-rings does not decrease monotonically with age, there are 'wiggles' superimposed on the exponential curve. Thus, for a given uncertainty in the measured ${ }^{14} \mathrm{C} /{ }^{12} \mathrm{C}$ for the sample to be dated, the uncertainty in the calibrated age depends on the location on the calibration curve. By tradition, ${ }^{14} \mathrm{C}$ laboratories also report the so-called 'conventional ${ }^{14} \mathrm{C}$ age' calculated from an assumed standard value for atmospheric ${ }^{14} \mathrm{C} /{ }^{12} \mathrm{C}$ and the so-called 'Libby ${ }^{14} \mathrm{C}$ half-life' of 5568 years. The ${ }^{14} \mathrm{C}$ dating method reaches $40-50,000$ years back, corresponding to a residual ${ }^{14} \mathrm{C}$ activity of only $2 \%$.

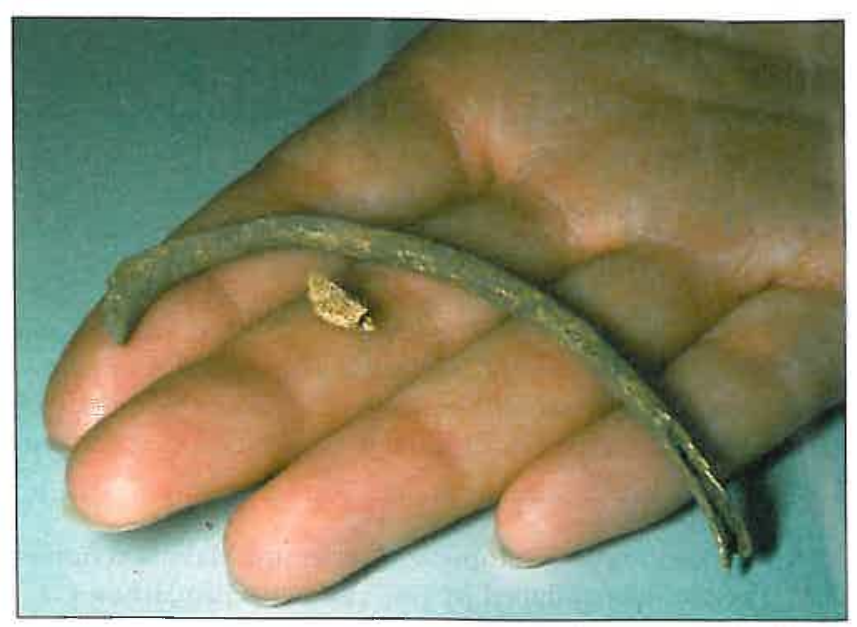

Fig. 2: A complete rib bone from an Iron Age infant and a small bone fragment. The small fragment represents all that is needed for ${ }^{14} \mathrm{C}$ dating with the AMS method. Not even the entire skeleton would provide sufficient material for a traditional ${ }^{14} \mathrm{C}$ dating.

The introduction of the AMS technique (Box 2 ) for ${ }^{14} \mathrm{C}$ dating has caused a break-through in Norse research in connection with the development of the AMS ${ }^{14} \mathrm{C}$ Dating Laboratory in Aarhus. A dating measurement with the AMS method requires less than one milligram carbon. This means that even small bone fragments can be dated (Fig. 2) with negligible destruction of invaluable archeological material.

The aim of our project was to carry out ${ }^{14} \mathrm{C}$ dating and stable isotope research on remains, mainly human bones from the entire Norse period in Greenland from both colonies, Eastern and Western Settlement. For this purpose, 27 human bones, 6 textiles and one ox bone were selected.

There were obvious difficulties: to establish a chronology within such short period (the colonisation lasted only 400-500 years) requires high dating accuracy. When dating humans, there is an added basic difficulty: the marine food chain has an apparent ${ }^{14} \mathrm{C}$ age about 400 years greater than the corresponding terrestrial food chain because carbon resides on the average 400 years longer in the ocean than in the atmosphere and the terrestrial biosphere. The difference is called the 'reservoir age'. This means that the bones of a Norseman who lived on salmon and seal will appear about 400 years older (when ${ }^{14} \mathrm{C}$ dated) than his twin brother, who lived on mutton and milk. If we were unable to account for the reservoir effect, a very "marine" Norseman from the end of the period might appear to be from the Landnam (initial settling) period.

\section{Stable carbon isotopes: a key to diet}

The solution to the problem was to measure the stable carbon isotope ratio in terms of the quantity $\delta^{13} \mathrm{C}$ (Box 3 ) from which the percentage of marine food can be determined. This in turn leads to an accurate reservoir-age correction to the ${ }^{14} \mathrm{C}$ age. The basic assumption is that any two persons with similar diet also exhibit identical $\delta^{13} \mathrm{C}$ values. This is strongly supported by the compilation of $\delta^{13} \mathrm{C}$ values of archeological bones, measured by international laboratories and in our laboratory (Fig. 4). This shows that the "terrestrial" people from inland Norway and Sweden cluster around a $\delta^{13} \mathrm{C}$ value of $-21 \%$. In contrast, Eskimos coinciding in time and place with the Greenland Norse show a narrow, "marine" distribution with a much higher $\delta^{13} \mathrm{C}$ of 
$-12.5 \%$, consistent with archeological expectations of an almost pure marine subsistence. Note that early Indians from the coast of British Colombia, although very marine, had greater access to terrestrial food, so that their spread in $\delta^{13} \mathrm{C}$ is greater because of individual freedom in the choice of food.

The $\delta^{13} \mathrm{C}$ values of the Greenland Norse are also shown in Fig. 4. These high-precision measurements were made with the mass spectrometer at the Science Institute in Reykjavik. The result is striking: The Norse data nearly cover the entire range between the terrestrial people from Norway and Sweden and the marine Eskimos from the Southwest coast of Greenland. Translated into diet composition, the corresponding range of marine food is as large as $20-80 \%$. This variation in diet is exceptionally high for a single culture in a very limited period of time. It could be due to individual preferences, possibly in connection with social differences, or it might reflect a temporal trend caused for example by a steady deterioration of the regional climate during the period as evidenced by recent ice-core research [5]. Resolving this question requires accurate ${ }^{14} \mathrm{C}$ dates corrected for the reservoir effect of the content of "old" marine food calculated for each individual.

\section{How to get accurate ${ }^{14} \mathrm{C}$ dates}

An important key to this question came from a particularly useful find from the churchyard at the locality identified as Herjolfsnes-the most southerly of the Norse settlements. During the excavation in 1921 [6], three skeletons were found laying close together, all wrapped in woollen clothes, which had been used for the burials presumably because of shortage of wood for coffins and fortunately preserved by permafrost through the intervening period. The textiles provide a unique opportunity to control the reservoir corrected ${ }^{14} \mathrm{C}$ age of the bones. The ${ }^{14} \mathrm{C}$ dates on a single thread of wool from each dress show that the graves are contemporaneous as expected from their relative positions.

Since sheep's wool is of terrestrial origin, there is no reservoir correction and the graves are reliably dated to AD 1430 with an uncertainty of only \pm 15 years - which makes it the youngest date so far with solid evidence of Norse presence in Greenland. One of the skeletons, a young woman (20-25 years), had an uncorrected

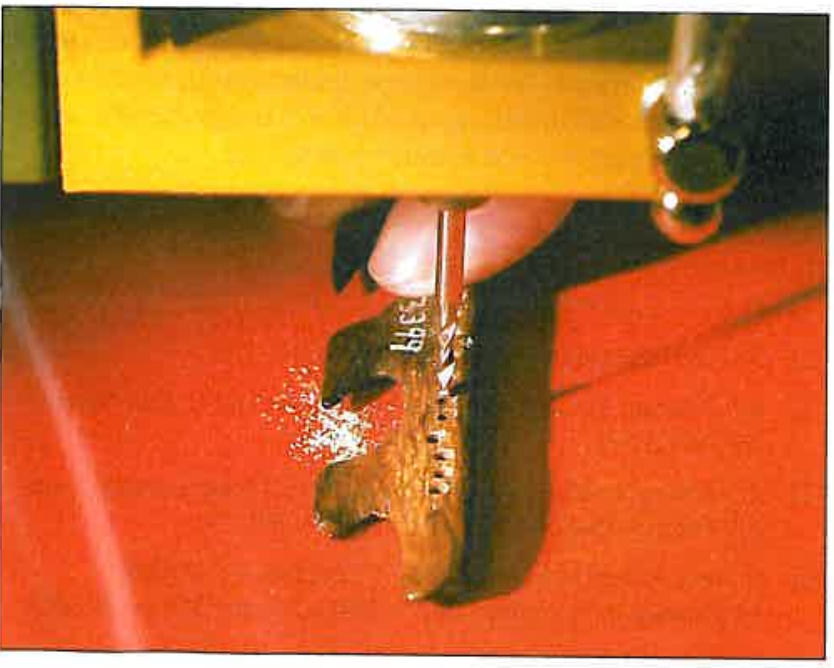

Fig. 3: Drilling of a sample for AMS ${ }^{74} \mathrm{C}$ dating from the tip of a harpoon made of deer antler. Samples of bone are drilled in the same way. Bone collagen is extracted from the sample and combusted into $\mathrm{CO}_{2}$ for isotope analysis and dating. Experience shows that collagen preserves the carbon isotopic ratios intact.

\section{Box 2}

\section{Carbon-14 dating with a tandem accelerator}

In the traditional ${ }^{14} \mathrm{C}$ method one determines the ${ }^{14} \mathrm{C}$ concentration by counting beta particles from the radioactive decay. Due to the long ${ }^{14} \mathrm{Ch}$ half-life and ensuing low decay rate this method is ineffective, requiring a sample size of at least one gram of carbon and long counting times. In Accelerator Mass Spectrometry (AMS) the ${ }^{14} \mathrm{C}$ atoms are counted directly. Because of the extremely low ${ }^{14} \mathrm{C} /{ }^{12} \mathrm{C}$ value, even in modern samples $\left(\approx 1.2 \cdot 10^{-12}\right)$, so far only tandem accelerators have been successful in providing sufficiently selective and accurate mass separation of the carbon isotopes. With a detection efficiency approaching $10 \%$ of the ${ }^{14} \mathrm{C}$ atoms in a sample, the AMS method allows dating of samples of less than $0.1 \mathrm{mg}$ carbon-10,000 times smaller than required for the traditional beta counting method. The uncertainty in an AMS-measurement can be as low as $0.2 \%$, corresponding to 20-30 ${ }^{14}$ C years.

${ }^{14} \mathrm{C}$ age which was 420 years older than her clothes and would place her shortly after Landnam. The two other skeletons, a child and an older woman, were approximately 250 years older than their clothes. However, the $\delta^{13} \mathrm{Cvalues}$ of the bones indicated a marine content of nearly $80 \%$ for the young woman and about $55 \%$ for the two others. The actual calculation can be simplified as follows: By subtracting the corresponding fraction of a fully marine reservoir age of 450 years from the bone ${ }^{14} \mathrm{C}$ date of each of the three individuals we obtain reservoir corrected dates, which then become identical with those of their clothes in all three cases. Thus, despite greatly differing marine contents, we feel confident that the method really is applicable for detailed individual corrections.

With the parameters fixed by this procedure, we could then correct all the bone dates of the project in a similar manner. They are shown in calibrated calendar years on the $x$-axes of Fig. 5, while the y-axes show the measured $\delta^{13} \mathrm{C}$ values and the inferred marine fractions in percent.

\section{Box 3}

\section{Stable isotopes}

Stable carbon is a mixture of $99 \%{ }^{12} \mathrm{C}$ and $1 \%{ }^{13} \mathrm{C}$. Conventionally, the isotopic ratio of a carbon sample is expressed in terms of $\delta^{13} \mathrm{C}$, defined as the relative deviation (in per mille) of the ${ }^{13} \mathrm{C} /{ }^{12} \mathrm{C}$ ratio of the sample from the ${ }^{13} \mathrm{C} /{ }^{12} \mathrm{C}$ ratio of a standard (PDB, a carbonaceous rock of marine origin). Since the rate constants of chemical reactions are slightly mass dependent, $\delta^{13} \mathrm{C}$ undergoes changes (isotope fractionation) in natural processes such as photosynthesis. Terrestrial plants assimilate carbon from atmospheric $\mathrm{CO}_{2}$ while marine plants assimilate from dissolved bicarbonate, leading to different $\delta^{13} \mathrm{C}$ values for plant material from terrestrial and marine environments. This difference persists throughout the two food chains. Thus, typical $\delta^{13} \mathrm{C}$ values for human bone collagen are $-21 \%$ if pure terrestrial food has been consumed, and $-12.5 \%$ if the food was purely marine.

Similarly, isotope fractionation of stable nitrogen isotopes is expressed via $\delta^{15} \mathrm{~N}$, the relative deviation of the ${ }^{15} \mathrm{~N} /{ }^{14} \mathrm{~N}$ ratio from a standard (air). The $\delta^{15} \mathrm{~N}$ value of bone collagen gives information on trophic level of the food (position in the food chain). 
Fig. 4: The plot shows how $\delta^{13} \mathrm{C}$ ( $x$-axis) clearly distinguishes people who have eaten terrestria! food from those who have eaten marine food (the $y$-axis only indicates grouping of the individual data series). Prehistoric people from inland Norway and Sweden cluster at the extreme right end of the plot close to $\delta^{13} \mathrm{C}=$ $-21 \%$, taken to be the purely terrestrial value. Greenland Eskimos and Indians from the West Coast of Canada are far to the left on the plot with the most marine values around $-12.5 \%$. The Greenland Norse data cover nearly the full range between these extremes. In our interpretation, the marine fraction of the food intake of this population ranges from $20 \%$ and up to $80 \%$ marine food - an exceptionally wide span in dietary habits for a population so concentrated geographically, culturally and chronologically.

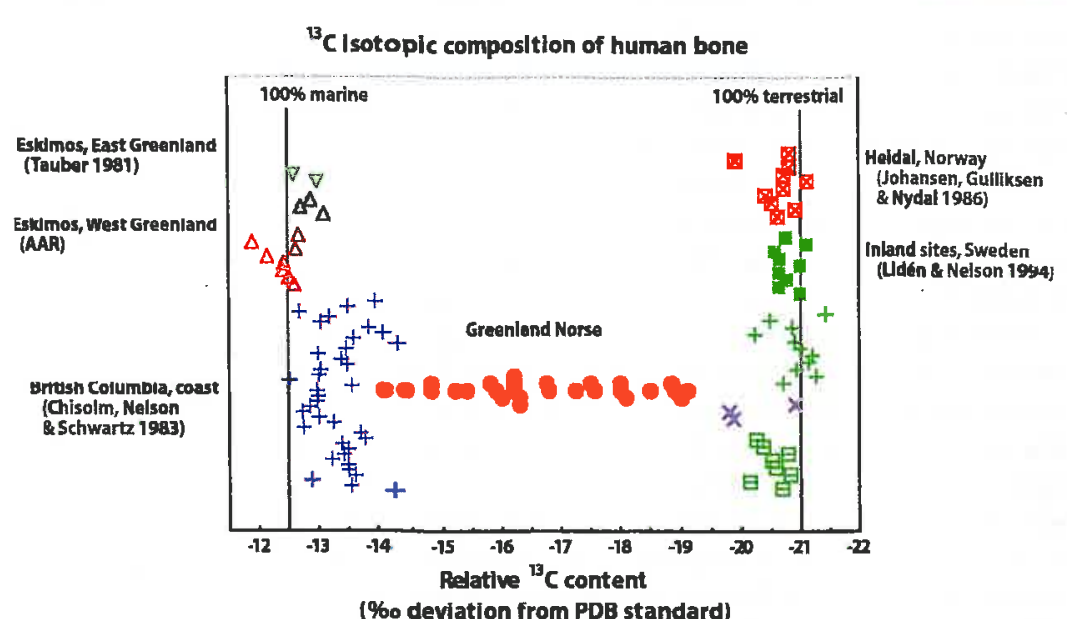

(\%o deviation from PDB standard)
Note that the earliest dates on human bones fall in the Landnam period (the 980's according to the written sources). These bones have been excavated from the churchyard around a tiny structure, which the archeologists have identified as the remains of the a church from around AD 1000 [7]. According to the sagas, Thjodhilde, the wife of Erik the Red, had it built close to their farm at Brattahlid and naturally the small church was named Thjodhilde's Church. Be it Thjodhilde's Church of the saga or not the church is one of the earliest archeologically known Norse constructions in Greenland. The ${ }^{14} \mathrm{C}$ date of an ox bone (terrestrial animal-no correction needed) from a grave in the same churchyard supports the early dates of human bones. Even though the

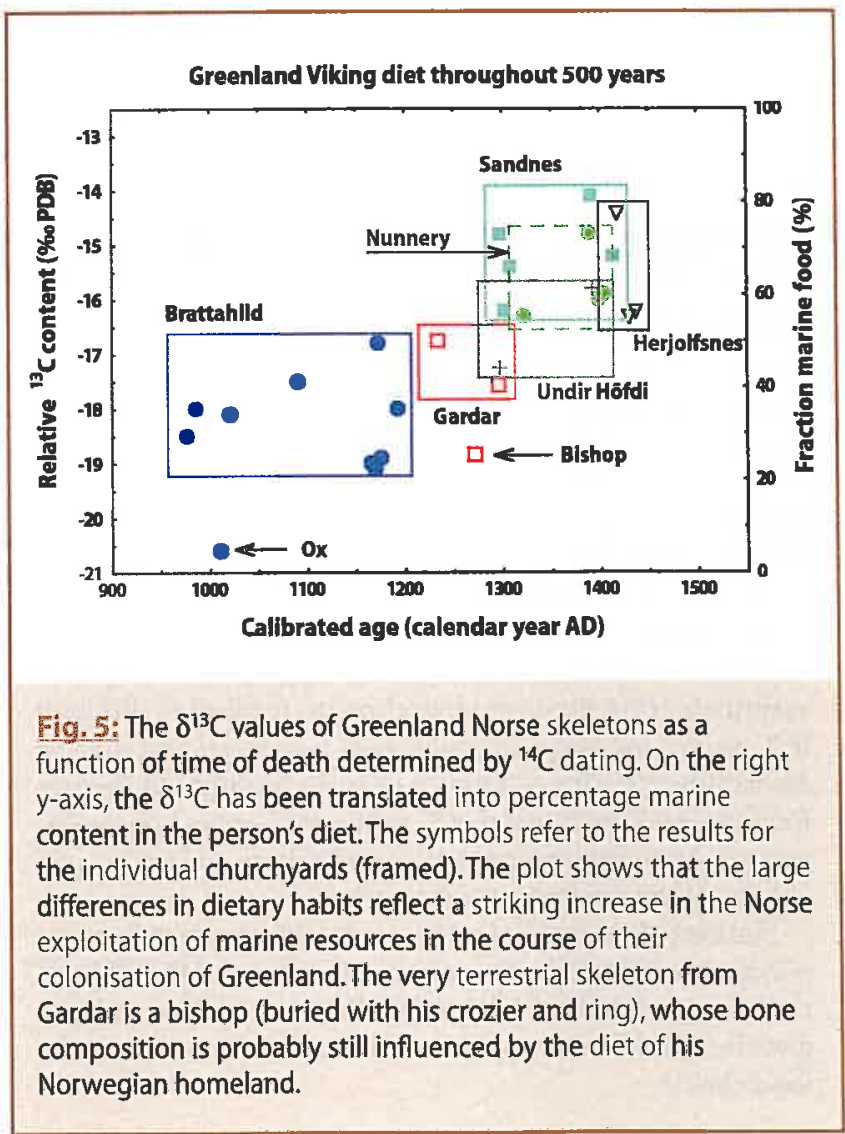

early human bones are only about $20 \%$ marine, it is absolutely essential to apply the corresponding correction. Otherwise, the dates would place the first settlers some 150 years earlier than historically acceptable.

\section{The Norse turn to sea food}

With a firm chronology thus established, we can read from Fig. 5 that the observed large differences in the marine content of the Norseman bones represent a striking increase in the Norse population's dependence on sea food during the period from Landnam till the depopulation of the settlements 4-500 years later. In the beginning, the diet of the settlers is approximately $20 \%$ marinemore or less like that of contemporaneous Norwegians. Towards the end of the period, an adaptation to marine resources has taken place-if only up to $80 \%$ of the level that we observe for contemporaneous Eskimos. Whether or not this dramatic change in the ways of life of the Norse in the course of only a few hundred years is due to the strain of a changing climate, or simply because more seals were available for the Norse hunters [8] must be left to future research to decide. But the present research at least can refute current speculations that the Norse finally succumbed because they were unable or unwilling to adapt to harsher climatic conditions by exploiting the rich resources of the sea.

\section{References}

[1] D. Elmore and F.M. Phillips, Science 236 (1987) 543

[2] M. Suter, Europhysics News 31/6 (2000) 16

[3] K.S. Petersen, K.L. Rasmussen, J. Heinemeier and N. Rud, Nature 359 (1992) 679

[4] J.Arneborg, J. Heinemeier, N. Lynnerup, H.L. Nielsen, N. Rud and Á.E. Sveinbjörnsdóttir, Radiocarbon 41 (1999) 157

[5] D. Dahl-Jensen, K. Mosegaard, N. Gundestrup, G.D. Clow, S.J. Johnsen, A.W. Hansen and N. Balling, Science 282 (1998) 268

[6] P. Nørlund, Meddelelser om Grønland 67 (1924) 1

[7] K.J. Krogh: Erik den Rødes Grønland. Nationalmuseet, København 1982

[8] A. Kuijpers, N.Abrahamsen, G. Hoffmann, V. Hühnerbach, P. Konradi, H. Kunzendorf, N. Mikkelsen, J. Thiede, W. Weinrebe, Geology of Greenland Survey Bulletin 183 (1998) 61 